\title{
Explore the Factors Affecting Behavioral and Psychological Changes On Obstetricians/Gynecologists in Maternal Health Care Center
}

\author{
Y. Hummaira Qudsia (Yousaf Hummaira Qudsia)1, M. Rehman (Muqaddas \\ Rehman) $)^{2}$
}

${ }^{1}$ PhD Scholar, Superior University, Lahore, PK

Original Article

${ }^{2}$ Assistant Professor, The University of Punjab, PK

\section{E-mail address:}

humaira.yousaf@superior.edu.pk

\section{Reprint address:}

Hummaira Qudsia Yousaf

PhD Scholar, Superior University

Lahore, PK

Source: Clinical Social Work and Health Intervention Pages: $24-35$
Volume: 9

Issue: 3

\section{Reviewers:}

Mario Bartkovjak - mariomario@yahoo.com

Andrea Shahum - ashahum@unc.edu

\section{Key words:}

Women's Health. Healthcare Center. Mental Health. Stress. Behavioral and psychological changes. Obstetricians/Gynecologists.

\section{Publisher:}

International Society of Applied Preventive Medicine i-gap

CSWHI 2018; 9(3): 24 - 35; DOI 10.22359/cswhi_9_3_03 @ 2018 Clinical Social Work and Health Intervention

\section{Abstract:}

Background: The quality of Doctors' services (informally or formally) due to behavioral and psychological changes is a scorching issue. In this study, Obstetricians/Gynecologists experiences are examined in maternal health settings to find out the factors affecting the behavioral and psychological health of the Doctors. 
Method: The current study is based on qualitative method in which the Case study approach is adopted. Ten interviews are conducted from obstetricians/gynecologist at their workplace.

Result: Through qualitative interviews, the findings revealed that $\mathrm{Ob}$ stetricians/Gynecologists deal with social pressure, excessive workload, social isolation, financial constraints and cultural adjustment. Our study discovered that such changes result in severe burn out, dissatisfaction, frustration, which results in diminishing the performance of Doctors, and ultimately influencing the service quality provided in Maternal Health Care Centers.

Conclusion: It suggests that policy makers, government and hospital's management should understand the requirements and demands of Doctors before preparing the service structure. In addition, it is recommended that the training sessions and seminar specifically designed to address the issues highlighted in the paper to help Doctors in improving their services.

\section{What do we already know about this topic?}

The Factors affect the behavioral and psychological changes on Practitioners is a scorching issue and need detailed investigation to improve the quality of service.

\section{How does your research contribute to the field?}

It introduced a new concept that, quality of service cannot be improved without knowing and improving the practitioner's mental health condition.

What are your research's implications towards theory, practice, or policy?

Theoretical: Introduced a new concept of Practitioners' mental health has impact on the quality of the service.

\section{Practical or Policy:}

1. Incorporate Physical activity

2. Encourage open communication

3. Arrange seminars and workshops to improve the commitment and attitude

\section{Introduction}

Maternity Care Centers hire trained professionals for perinatal health care and delivery of newborns. Their professional team includes trained and experienced Obstetricians/Gynecologists, Nurses, Midwives and other associative staff. Maternity Care Centers are mainly developed to provide full time availability, easy accessibility and acceptability of pre-delivery, and post-delivery services (Arulkumaran, 2010). Guercini, La Rocca, Runfola, \& Snehota (2014) proposed that the quality of these services can be standardized and improved mainly by having an effective Doctor-patient relationship. Obstetricians/Gynecologists are Specialists in the area of reproductive health care in women. The infinitesimal difference between an Obstetrician and Gynecologist is that Obstetrics deals especially with pregnancy and birth related issues while Gynecology is the study of women's reproductive system as a whole.

The term Clinical Governance can be defined as "a framework which holds the health service providers and health organizations accountable for continuous evolution and 
improvement of the health services quality and safety according to high standards by maintaining an atmosphere where clinical care quality will evolve" (Raghupathi \& Raghupathi, 2014). Horvath et al. (2011) combined the organizational, managerial and the clinical approaches in order to improve the clinical care quality by making such systems and procedures which would be helpful in maintenance of present good clinical practices, while allowing the policy makers to make improvements in the general health care structures.

The most crucial part constituting Clinical Governance is "Doctors“. Licata \& Klein (2010) concluded the clinical monarchy-based relationship between a Doctor and a patient is usually viewed as benevolent paternalism having factors like attitude, behavior and language as the key relationship elements. According to McCabe (2004), to establish a trustworthy Doctor-patient relationship, empathetic listening and effective communication are the essential factors. It thus leads to building a connection which allows the patients the expression of their feelings, emotions and thoughts. In turn, the transmission of the diagnostics, suggestions, recommendations and the appropriate treatment can be done in an effective way. Proper attention, care and vigilance towards Doctors may cause changes in their emotional and psychological aspects. It becomes crucial to strap the parent-Doctor relationship in Maternity Centers where emotional and behavioral changes may affect the relationship in an inappropriate manner.

Health psychology is the term which deals with the mental and behavioral procedures in health and illness. Avery \& Patterson (2017) stated that health psychology also deals with the way in which psychological and behavioral elements contribute to physical health and physical illness. Psychological elements can have direct effects on health. (Kowpak \& Gillis, 2015) stated that appropriate health policies for the general public requires proper attention on the mental health of Doctors. This paper argues the importance of mental health of both Doctors and Specialists. A Doctor's mental health should be given importance for the following main reasons. First, being a major contributor in providing the health facilities, Doctors should have a healthy mind in order to give a healthy output. Secondly, the nature of Doctors' work is very sensitive because the life and health of the patient is in their hands and even a single mistake may result into unforgettable casualty. Third, the satisfaction and impaction of a Doctor services is a blessing for those women who are in a life-threatening stage. This study aims to find out and discuss the factors that have influence on the psychological and the behavioral health of a Doctor and also provides suggestions to address these influences.

\section{Literature Review}

Pakistan lies sixth of most populated countries of the world having a population of more than 201 million people. About $48.63 \%$ of this population is constituted by women. According to the World Bank collection of development indicators as published in 2015, only one Health Care Center is available for 500 persons on average. The Maternal mortality ratio is 178 for per 100,000 births (WHO, 2016). According to WBDI (2014), on average only six Midwife/Nurse are available for almost 1,000 people in Pakistan. These statistics show the alarming situation.

There are many challenges faced by the system of Maternal Healthcare in Pakistan. Some of these challenges are: ensuring the availability of trained staff in Maternal Health Care Units; expansion and improvement of the services provided to mothers and their children; appropriate managerial 
skills to address the attitude and other psychological problems in Doctors as well as patients; collection of adequate funds for Maternal Health Care Services. Doctor to patient ratio is very small which in turn increases the work load on Doctors causing frustration, aggression and other attitude problems in them. Many complaints have been registered by the patients about rude and inappropriate behavior of Doctors particularly in Maternity Centers.

It is very obvious that the life of a Doctor, especially a Gynecologist or Obstetrician which is very busy and complex, as he has to be on duty for a very long time; has to deal with critical situations; has to sacrifice their personal life; emotions and thoughts remain unexpressed (Balch et al., 2009). He/ she works in a complex medical atmosphere where his/her behavior and psychological health is badly affected. Research shows that the passion and commitment of a person to himself and his life domains reveals his psychological health (Kashdan \& Rottenberg, 2010). According to Lazarus and Folkman (1984), the relationship between the environment and individuals in which an individual respond through emotional, behavioral and physiological mechanism is called stress. Poor psychological health is due to mental stress; this process involves variables and controlling factors associated with coping and appraisal processes. Although, the majority of Doctors honestly put patients' care at first priority instead of profit but there are a number of incidents where patients told about the illegal practices of the Doctors for monetary purposes.

Various studies on the mental health of Doctors suggest the psychological health of Doctors is usually low compared to other professions (Kinman, 2001). Human psychological and behavioral changes are long or short processes and not just an event, hence it is vigorous to comprehend what elements stimulate such changes; how such changes occur; what elements trigger them (Holmes, 2010). Many studies suggest different names for the psychological health such as ego-resiliency (Block, 1961), self-regulation (Muraven \& Baumeister, 2000) and executive control (Posner \& Rothbart, 1998). The societal shifts during the last few decades lead to the empowerment of individuals in comparison to institutions and government authorities, initiating the rights-based movements like patients ${ }^{6}$ rights; women's rights; consumers' rights; minority groups' rights; etc.. Doctors and Specialists used to feel that their rights still need attention, even though many people think of Doctor as a "Priest" and their attitude hurts the feelings and ego of such people. Davis, Campbell, Hildon, Hobbs \& Michie (2015) explained that to maximize the latent effectiveness of interferences it is essential to comprehend behavior and behavioral changes. In simple words, the complete understanding of behavioral changes.

Medical experts can't neglect the changes they face while serving in Maternal Care Centers. These changes happen in biological, psychological and behavioral areas. (Sallis, Owen \& Fisher 2015) suggested a Social Ecological Model (SEM) for understanding the psychological and behavioral changes among Doctors; he says that multi-faceted and interactive influences of personal and atmospheric elements can be employed to find the changes in behavior. Social ecology deals with the relations between human beings and their active context and settings. Human behavior is influenced by multiple levels: intrapersonal (including biological and psychological); interpersonal (including cultural and social); physical surrounding; organizational community; policies. Helping the progress of more comprehensive interventions through explicit consideration of multiple levels of influences, is the core concept of social ecological model (Golden \& Earp, 2012). Several 
researchers suggest that the psychological well-being can be earned from traditional and egalitarian values and satisfaction of the competence and autonomy requirements (Deci \& Ryan, 2008). Social forces and interpersonal environment influence motivation (controlled and autonomous). Young and Koopsen (2010), elaborated physical and mental health is important; a holistic approach towards health would focus on emotional states, spiritual aspects and social circumstances. Good health provides an ability to meet life's challenges, opportunities and maintain a level of functioning that has a positive influence on well-being.

Psychological flexibility increases human capabilities to: maintain the work-life balance; make commitment towards their values; be open minded; have cognitive abilities and increased emotional intelligence (Kashdan \& Rottenberg, 2010).

The philosophy of Health Care encourages the Health Care Team to treat patients with respect, honor, dignity and compassion; thus, making a trustworthy and strong relationship with patients and caretakers. This paper includes interviews from several Doctors to discover the factors which cause psychological and behavioral changes in them. Behaviors in reality, increase the well-being, whereas others do not.

Table 1:
The investigation of this study's focal phenomena warranted an holistic approach and the use of combined research methods i.e. semi-structured interviews and observations. Such insights may best be facilitated through a case study design. This form of enquiry investigates contemporary phenomenon within its real life context. It is particularly useful in settings such as Health Care, where boundaries between phenomenon and context are unclear, and where contextual conditions are also highly pertinent.

\section{Method}

Study Setting: To investigate the research question where contextual conditions are highly pertinent and boundaries between phenomenon and context are unclear (Yin 2015, Yin \& Davis 2007) semi-structured interviews and observations may be the best method to warrant an holistic approach (Eisenhardt 1989). Here the Case Study approach is employed as the research aims to discover the factors that affect the service quality in Maternal Care Centers in Pakistan. Case Study being an appropriate method is focused on collecting experiential knowledge and influence of its political, social and other contexts (Crowe et al., 2011).

Ten Gynecologist/Obstetrician are identified who are appointed in Maternal Health Care Centers of the Punjab. Using

\begin{tabular}{|c|c|c|c|c|c|c|}
\hline & Pseudonyms & Length of service & Gender & Age & Posting & Residual \\
\hline 1 & $\mathrm{R} 1$ & 10 & $\mathrm{~F}$ & 40 & RahimYar Khan & Lahore \\
\hline 2 & $\mathrm{R} 2$ & 8 & $\mathrm{~F}$ & 35 & Multan & Lahore \\
\hline 3 & R3 & 14 & $\mathrm{~F}$ & 40 & Bahwalnagr & Gujranwala \\
\hline 4 & $\mathrm{R} 4$ & 4 & $\mathrm{~F}$ & 34 & Gujranwala & Sahiwal \\
\hline 5 & $\mathrm{R} 5$ & 10 & $\mathrm{~F}$ & 40 & Bahawapur & Bahawalpur \\
\hline 6 & R6 & 15 & $\mathrm{M}$ & 41 & Lahore & Bahawalnagar \\
\hline 7 & $\mathrm{R} 7$ & 5 & $\mathrm{~F}$ & 34 & Lahore & Bahawalnagar \\
\hline 8 & $\mathrm{R} 8$ & 10 & $\mathrm{~F}$ & 40 & Sahiwal & Multan \\
\hline 9 & R9 & 15 & $\mathrm{M}$ & 41 & Bahawalpur & Lahore \\
\hline 10 & R10 & 12 & $\mathrm{M}$ & 38 & Lahore & Lahore \\
\hline
\end{tabular}


convenience sampling, representativeness is limited in this study. However, demographic variables are controlled. For example, participants are selected from different cities, such as, Lahore, Dera Ghazi Khan, Bahawalpur, Sahiwal and Lahore. Based on convenience sampling, it was experienced that participants are more open and it helped us to gather in depth data. We met them at their workplace according to their convenience. Interview sessions were held at the workplace or participant's home as per their convenience. Each interview lasted 70 minutes and all Interviews were audio-taped. The interview questions were mainly related to the experiences of Doctors since they joined a Maternal Health Care Unit. We adopted the semi-structured interview in this study. Thus, each participant replied to the same research questions and information was explored on the basis of their responses. This approach is fixated on the respondent's point of view rather than making generalizations about behavior. Interviews were conducted primarily in English and transcribed immediately afterwards.

Notes and researcher's reflections were also prepared to cross check with interview transcripts later.

The data obtained over in-depth interview was thematically analyzed using NVivo 10 . The main themes were extracted after thematic analysis and content analysis was also made to confirm these themes.

\section{Results}

The findings revealed that there are many factors which influence the psychological and behavioral changes in medical experts serving in Maternal Health Care Units. They are facing a continuous battle to deal with the changes in order to perform their duties. Four main themes are generated related to the factors that affect the behavioral and psychological changes.

\section{Communication}

Researchers' evidence shows that communication among the healthcare team with the patients and their attendants is considered to be the most crucial and highly emphasized factor in order to improve the quality of services in the Maternal Health Care Centers (Mooney et al., 2009).

"I always avoid to talk on non-clinical issues, even though most of the times the main source of problems are the non-clinical issues." (R1)

According to (Huntington \& Kuhn 2003) the biggest malpractice in Health Care is a communication gap between Doctors and their patients. The same concern was expressed by many of the respondents.

"Sometimes the communication gap makes me upset. In a Maternity Ward a patient can communicate with us directly as the one who can listen to their non-clinical issues and give them better suggestions. But I feel patients avoid to discuss non-clinical issues with me due to family restrictions as I am appointed in the Rural Health Care Centers. My patients mostly are illiterate. At the start, I tried again and again to facilitate them, but now I leave it and just focus on the clinical issue." (R3)

Another respondent stated in this respect:

"Well, culturally people are very rigid here and they don't want to come out. I have many female patient who do not want to talk. They are always trying to influence the Doctor and deceive them. It's very difficult for me to communicate with them." (R2)

"Patients never tell the exact history and never accept her/his mistake that they had consulted any quakes; use any folk method; 
mostly believes that he knows more than me and always argue unnecessarily to show her/his knowledge so that mostly irritates me."(R6)

The interview data highlights that strong communication is necessary between the patient and his Doctor, otherwise stress is generated which leads to medical error.

\section{Excessive Workload}

Workload is linked with various harmful psychological reactions like emotional exhaustion and lowered worked efficiency (Himle, Jayaratne, \& Thyness 1991); (Greenglass, Burke, \& Moore 2003, Himle et al., 1991).

"I don't want to tired but I become tired. Sometimes I checked more than 30 patients in a day and it diminished my performance." (R9)

Walker (1996) stated that high workload causes stress, cynicism, frustration, and burnout. Burnout leads to health problems; circadian misalignment during shift work; impaired social life; sleep disorders (Åkerstedt \& Wright 2009).

"Excessive work had raised my family conflicts. Sometimes, I referred my patient for some test because I did not have time to evaluate the patient's condition." (R7)

"Excessive workload causes stress in me. To cope with the stress, I used to smoke (after a burst of laughter) I know I am a Doctor, but this is my only solution to deal with stress" (R10)

"Health scenario of Pakistan BHU and RHC and DHQ's are not fully functional so patients with minor illness also come to tertiary care hospitals which are meant to deal with advanced diseases. Doctors working there are overburdened to deal with those patients" (R3)

"As the Doctor to patient ratio in our practice is in the negative, our Doctors have to spend 24 hour duties in emergencies and this decreases efficiency and makes me frustrated" (R1)

"My duty hours are mostly from 8 to 3 that really tired me and these are the theoretical timings. But practically being a Gynecologist, I am on duty all the time which results in aggressive and rude behavior. To cope with all this, I mostly use tea like water but that is also of no use now". (R5)

\section{Cultural Adjustment/Social Isolation}

Many researchers reported that social isolation produces neurochemical, psychological and behavioral influences (Bitterman 1965; File, Mabbutt \& Toth 1990); (Fulford, Butler, Heal, Kendall, \& Marsden, 1994).

"I am in a phase of social isolation. I belong to Lahore, and in D G Khan there is no proper place for outing, hotel, park or shopping mall. As my husband is also a government employee in Multan I felt myself alien when I come out without him. I have to go out to perform various tasks such as drop off and pick up my children in school; get groceries; and..., etc.,. He used to visit us on holidays"(RI)

Ali, Van der Zee \& Sanders (2003) suggest that the process of adaptation is dealing with cross-cultural transitions while its outcome is adjustment. General adaptation refers to expatriates' degree of psychological comfort with regard to several aspects such as Health Care, climate, food and accommodation; however communication 
adaptation evaluates expatriates' efforts to founding relationships with the locals.

"My main problem is making friends in this new city. My family and friends are from Lahore. It's difficult for me to settle my family in this city (Sahiwal). I am waiting for holidays to go to Lahore and spend time with my family and friends" (R4)

"I tried my best for my appointment in my own city but I failed. It is difficult to bear the cost of living in Lahore, as I lived in a joint family system. My family lived with my parents in Bahawalnagar. I am performing two jobs in a day. That's why I have no time for friendship." (R2)

"Due to long working hours I find no time for me and my family as much as should be. I have no time for friends and hangouts. Due to this I am mostly frustrated that really effects my life. I am always in a hurry to complete my work at home so that I can get to hospital on time. That's some time that makes me want to quit." (R8)

\section{Limited Availability of Resources}

Schaufeli \& Enzmann (1998) concluded that without adequate resources and support, psychological contract with their employees has been eroded.

"In hospital resources such as wheel chairs, ambulances, medicines, surgical instruments and etc. are limited. The hospital has three ambulances but they are constantly breaking down." (R6)

"Water shortage is the most acute problem in the hospital since it is constructed on high ground and WASA is failing to pump enough water. There are limited beds in the maternity ward and many times we settle two patients on a single bed. " (R3)
"We are short of surgical instruments. Due to unavailability of required equipment most of cases are referred to the District Hospital which is $75 \mathrm{~km}$ away. At times, patients die while traveling ng there. That's why in this hospital, the death ratio of female patients is more than males." (R5)

"There is an ultrasound problem, so I refer them to do the scan privately. I feel bad for the patients as most of them are poor. " (R1)

"We are short of surgical instruments, medicine and proper environment that sometimes badly effects the case and patient dies due to non-availability. Because of all this, patients mostly prefer to go to private clinics." (R8)

\section{Discussion:}

Based on the findings of this study, recommendations can be made for the Doctors and policy makers in Pakistan to take effective steps in order minimize the factors discovered above, which are adversely influencing the psychological and behavioral changes in Maternal Health Care Centers.

Communication is the main theme of this research which can directly influence the service quality of Doctors. It's the responsibility of both the Doctors and patients to communicate with each other in all the stages of service delivery. Developing communication and managing emotions may reduce amygdala activation integrated with reduced emotional dysregulation and highlighting the possible neural impact of satisfaction (Kozlowska, Walker, McLean \& Carrive (2015). Language is the main barrier with any communication, therefore Doctors should not be appointed far from their hometowns. Additionally, appointment of Doctors in nearby premises may also solve many problems of cultural adjustment 
and social isolation. Another solution is to appoint more local Lady Health Visitors (LHV) and Midwives because they are well aware of the culture and language of local population. Cross cultural adaptation, social network and integration into behavior and values are the most important facilitators (Étémé, Girard, Massé \& Sercia, 2016).

The study result also discovers that excessive workload and poor working environment causes stress, work-family conflicts and burnout which ultimately influence the quality of service. Two broader dimensions of a working environment are work and context. Work comprises all the different physiognomies of the job like task activities training; the way a job is carried out and completed; a sense of achievement from work; control on one's own job related activities; diversity in tasks; the central value for a task (Gazioglu \& Tansel 2006; Skalli, Theodossiou \& Vasileiou 2008; Sousa-Poza \& Sousa-Poza, 2000). To overcome this problem, human resource management programs should be initiated at the national level. It is necessary for management to improve the working conditions for the satisfaction of employees working under difficult working conditions. This will satisfy them and in return overall performances will increase. The motivational factors (acknowledgement or appreciation; the sense of achievement from their work; the nature of work; opportunities for personal growth and advancemen; the responsibility that is granted to them) help employees to find the value, respect and worth given to them by their organization (Dartey-Baah \& Amoako, 2011; Raziq \& Maulabakhsh, 2015)

Educational programs including motivation, stress management, emotional intelligence and work-life balance should be started at the national level. Continuous training and seminars can also prove helpful to improve psychological and behavioral health. The impact of training is higher for the white collar jobs because of less effectiveness of materialistic output (Ackerberg, Caves \& Frazer (2006). Availability of the required resources in Maternity Health Care Centers is the prime responsibility of the government; policy makers should focus on the utilization, maintenance and distribution of these resources.

\section{Conclusion:}

By employing the qualitative research method, the factors which influence the psychological and behavioral changes are explored in this research. The findings indicate that Obstetricians/Gynecologists in Maternal Health Care Hospitals deal with a series of factors that affect their behavior. The effect of these factors can be minimized by changing their lifestyle; by revising the work strategy; by adopting a positive attitude and commitment towards work. The governments' responsibility is to provide the required resources to the Doctors and help them to address these influencing factors. Government and policy makers need to focus these factors faced by Doctors and provide appropriate support to them.

The study employed a small sample of Ten Obstetricians/Gynecologists from Pakistan. The validity of the study is contingent upon the interpretation of interviews; it only focused the problems faced by Obstetricians/ Gynecologists in hospital settings; however, by including family issues being faced by Obstetricians/Gynecologists into the study more vital themes can emerge. The main limitation of this research is population size and sampling strategy; despite these limitations, the results have the impetus to contribute in the development of Health Care reforms providing data and information on the factors that influence psychological and behavioral changes in Doctors. 
Abbreviations:

OB / GYN: Obstetricians/Gynecologists LHV: Lady Health Visitor

Declarations: Availability of data and materials: The datasets analyzed during the current study are available from the corresponding author on reasonable request.

Funding: Authors did not receive any funding from the external source.

Competing interests: The authors declare that they have no competing interests.

Consent for publication: After fully explaining the details of the study, written consent was obtained from all the study participants for the interview, tape recording, and for publication. Participants were not reimbursed for participating in the study.

Ethics approval and consent to participate: After the approval of the research proposal from ANCRD (Azra Naheed Center for Research and Development), the researchers were advised to first obtain ethical approval from the Azra Naheed Health Committee (University Teaching and Research Ethic Committee). Approval was given by the Committee to the manuscript Explore the Factors affect the behavioral and psychological changes on Obstetricians/Gynecologists in Maternal Health Care Center (Protocol Number Sp-222). After fully explaining the details of the study, written consent was obtained from all study participants for interviews, tape recording, and for publication. All respondents agreed to allow recording.

\section{References}

1. ACKERBERG D, CAVES K, FRAZER G (2006) Structural identification of production functions.

2. AKERSTEDT T, WRIGHT K P (2009) Sleep loss and fatigue in shift work and shift work disorder. Sleep medicine clinics, 4(2), 257-271.

3. ALI A, VAN DER ZEE K, SANDERS G (2003) Determinants of intercultural adjustment among expatriate spouses. International Journal of Intercultural Relations, 27(5), 563-580.

4. ARULKUMARAN S (2010) Clinical governance and standards in UK maternity care to improve quality and safety. Midwife$r y, 26(5), 485-487$.

5. AVERY N, PATTERSON S (2017) Physical Health in Public Mental Health Care: A Qualitative Study Employing the COM-B Model of Behavior to Describe Views and Practices of Australian Psychologists. Australian Psychologist.

6. BALCH C M, GERSHENWALD J E, SOONG S J, THOMPSON J F, ATKINS M B, BYRD D R, ... DING S (2009) Final version of 2009 AJCC melanoma staging and classification. Journal of clinical oncology, 27(36), 6199-6206.

7. BITTERMAN M E (1965) Phyletic differences in learning. American Psychologist, 20(6), 396.

8. BLOCK J (1961) The Q-sort method in personality assessment and psychiatric research.

9. CROWE S, CRESSWELL K, ROBERTSON A, HUBY G, AVERY A, SHEIKH A (2011) The case study approach. BMC medical research methodology, 11(1), 100.

10. DARTEY-BAAH K, AMOAKO G K (2011) Application of Frederick Herzberg's Two-Factor theory in assessing and understanding employee motivation at work: a Ghanaian Perspective. European Journal of Business and Management, 3(9), 1-8.

11. DAVIS R, CAMPBELL R, HILDON Z, HOBBS L, MICHIE S (2015) Theories of behavior and behavior change across the social and behavioral sciences: a scoping review. Health psychology review, 9(3), 323-344.

12. DECI E L, RYAN R M (2008) Facilitating optimal motivation and psychological well-being across life's domains. Canadian Psychology/Psychologie canadienne, 49(1), 14. 
13. EISENHARDT K M (1989) Agency theory: An assessment and review. Academy of management review, 14(1), 57-74.

14. ETEME G, GIRARD A, MASSE J C, SERCIA P (2016) Do acculturation strategies have impacts on the self-declared health, well-being and lifestyle of first-generation allophone immigrants in Montreal, Canada? International Journal of Migration, Health and Social Care, 12(1), 66-82.

15. FILE S E, MABBUTT P, TOTH E (1990) A comparison of the effects of diazepam and scopolamine in two positively reinforced learning tasks. Pharmacology Biochemistry and Behavior, 37(4), 587-592.

16. FOLKMAN S (1984) Personal control and stress and coping processes: A theoretical analysis. Journal of personality and social psychology, 46(4), 839.

17. FULFORD A J, BUTLER S, HEAL D J, KENDALL D A, MARSDEN C A (1994) Evidence for altered $\alpha 2$-adrenoceptor function following isolation-rearing in the rat. Psychopharmacology, 116(2), 183-190.

18. GAZIOGLU S, TANSEL A (2006) Job satisfaction in Britain: individual and job related factors. Applied economics, 38(10), 1163-1171.

19. GOLDEN S D, EARP J A L (2012) Social ecological approaches to individuals and their contexts: twenty years of health education \& behavior health promotion interventions. Health Education \& Behavior, 39(3), 364-372.

20. GREENGLASS E R, BURKE R. J, MOORE K A (2003) Reactions to increased workload: Effects on professional efficacy of Nurses. Applied psychology, 52(4), 580-597.

21. GUERCINI S, LA ROCCA A, RUNFOLA A, SNEHOTA I (2014) Interaction behaviors in business relationships and heuristics: Issues for management and research agenda. Industrial Marketing Management, 43(6), 929-937.

22. HIMLE D P, JAYARATNE S, THYNESS P (1991) Buffering effects of four social support types on burnout among social workers. Paper presented at the Social Work Research and Abstracts.

23. HOLMES S H (2010) Being at home with your self: A feminine journey through developmental transitions: Pacifica Graduate Institute.

24. HORVATH M M, WINFIELD S, EVANS S, SLOPEK S, SHANG H, FERRANTI J (2011) The DEDUCE Guided Query tool: providing simplified access to clinical data for research and quality improvement. Journal of biomedical informatics, 44(2), 266-276.

25. HUNTINGTON B, KUHN N (2003) Communication gaffes: a root cause of malpractice claims. Proceedings (Baylor University. Medical Center), 16(2), 157.

26. KASHDAN T B, ROTTENBERG J (2010) Psychological flexibility as a fundamental aspect of health. Clinical psychology review, 30(7), 865-878.

27. KINMAN G (2001). Pressure points: A review of research on stressors and strains in UK academics. Educational psychology, 21(4), 473-492.

28. KOWPAK D, GILLIS L (2015) Aboriginal Mental Healthcare in Canada: The role of alternative service delivery in transforming the provision of mental health services. Dalhousie Journal of Interdisciplinary Management, 11 .

29. KOZLOWSKA K, WALKER P, MCLEAN L, CARRIVE P (2015) Fear and the defense cascade: clinical implications and management. Harvard review of psychiatry, 23(4), 263.

30. LICATA L, KLEIN O (2010) Holocaust or benevolent paternalism? Intergenerational comparisons on collective memories and emotions about Belgium's colonial past. International Journal of Conflict and Violence, 4(1), 46.

31. MCCABE C (2004) Nurse-patient communication: an exploration of patients' experiences. Journal of clinical nursing, 13(1), 41-49. 
32. MOONEY R A, DAVIS S E, PETERS J M, ROWLAND J L, ANSARI A Z, LANDICK $\mathrm{R}$ (2009) Regulator trafficking on bacterial transcription Units in vivo. Molecular cell, 33(1), 97-108.

33. MURAVEN M, BAUMEISTER R F (2000) Self-regulation and depletion of limited resources: Does self-control resemble a muscle? Psychological bulletin, 126(2), 247.

34. POSNER M I, ROTHBART M K (1998) Attention, self-regulation and consciousness. Philosophical Transactions of the Royal Society of London B: Biological Sciences, 353(1377), 1915-1927.

35. RAGHUPATHI W, RAGHUPATHI V (2014) Big data analytics in healthcare: promise and potential. Health information science and systems, 2(1), 3.

36. RAZIQ A, MAULABAKHSH R (2015) Impact of working environment on job satisfaction. Procedia Economics and Finance, 23, 717-725.

37. SALLIS J F, OWEN N, FISHER E (2015) Ecological models of health behavior. Health behavior: theory, research, and practice. 5th ed. San Francisco: JosseyBass, 43-64.
38. SCHAUFELI W, ENZMANN D (1998) The burnout companion to study and practice: A critical analysis: $C R C$ press.

39. SKALLI A, THEODOSSIOU I, VASILEIOU E (2008) Jobs as Lancaster goods: Facets of job satisfaction and overall job satisfaction. The journal of socio-economics, 37(5), 1906-1920.

40. SOUSA-POZA A, SOUSA-POZA A A (2000) Well-being at work: a cross-national analysis of the levels and determinants of job satisfaction. The journal of socio-economics, 29(6), 517-538.

41. WALKER C (1996) Signs of the Wild: Struik.

42. WHO U (2016) UNFPA: World Bank, Trends in maternal mortality: 1990-2010. 2012. Google Scholar.

43. YIN R K (2015) Qualitative research from start to finish: Guilford Publications.

44. YIN R K., DAVIS D (2007) Adding new dimensions to case study evaluations: The case of evaluating comprehensive reforms. New directions for evaluation, 2007(113), 75-93.

45. YOUNG C, KOOPSEN C (2010) Spirituality, health, and healing: An integrative approach: Jones \& Bartlett Publishers. 